association of premature emphysema in ZZ homozygotes who smoke.

\section{S62 CHARACTERISATION OF A NOVEL "PSEUDO-Z" VARIANT OF a1-ANTITRYPSIN}

doi:10.1136/thx.2010.150938.13

\begin{abstract}
${ }^{1} \mathrm{M}-\mathrm{P}$ Nyon, ${ }^{1} \mathrm{~L}$ Segu, ${ }^{2} \mathrm{~B}$ Roussel, ${ }^{3} \mathrm{~N}$ Kalsheker, ${ }^{2} \mathrm{D}$ A Lomas, ${ }^{1} \mathrm{~K}$ Thalassinos, ${ }^{1} \mathrm{~B}$ Gooptu. ${ }^{1}$ Institute of Structural and Molecular Biology, University College London and Birkbeck College, University of London, London, UK; ${ }^{2}$ Department of Medicine, University of Cambridge, Cambridge Institute for Medical Research, Cambridge, UK; ${ }^{3}$ Division of Clinical Chemistry, University Hospital, Queens Medical Centre, Nottingham, UK
\end{abstract}

The $Z$ (Glu342Lys) variant of $\alpha_{1}$-antitrypsin is common in populations of North European descent. The mutation causes individual $\alpha_{1}$-antitrypsin molecules to assemble into polymer chains in the endoplasmic reticulum of hepatocytes. $Z$ homozygotes (PiZZ) have circulating levels of $\alpha_{1}$-antitrypsin $\sim 15 \%$ of normal and are predisposed to hepatic cirrhosis and severe, early-onset emphysema. The risk of clinically significant disease associated with the heterozygote PiMZ state is minimal. We describe a case phenotyped as PiZZ during family screening, but with surprisingly preserved circulating $\alpha_{1}$-antitrypsin levels. Genotyping revealed compound heterozygosity for the Z mutation and a novel, "pseudo- $Z$ " mutation. Biochemical and ion-mobility mass spectrometry characterisation of pseudo- $Z \alpha_{1}$-antitrypsin showed that it readily populated a polymerogenic intermediate state under physiological conditions. Cell biological studies of a series of $\alpha_{1}$-antitrypsin variants indicated these effects involved disruption of a hydrogen bond stabilising the F-helix-linker region of the protein structure. These data strongly support the hypothesis that stability of this region co-regulates formation of the polymerogenic intermediate. Whilst the intermediate form of pseudo- $Z \alpha_{1}$-antitrypsin is more stable than that of the true $Z$ variant, the resultant polymers all share a characteristic neoepitope. Pseudo-Z $\alpha_{1}$-antitrypsin is thus a useful model for in vitro screening of potential lead compounds to bind the polymerogenic intermediate state, improving the ability to develop novel therapies to treat $\alpha_{1}$-antitrypsin deficiency. Our data predict that the likelihood of severe disease in the PiZ/Pseudo-Z compound heterozygote state will be increased relative to the PiMZ state, but far lower than for PiZZ individuals.

\section{S63 USE OF NMR SPECTROSCOPY AND NANOSPRAY MASS SPECTROMETRY TO CHARACTERISE BINDING OF LEAD COMPOUNDS FOR DRUG DESIGN IN $\propto 1$-ANTITRYPSIN DEFICIENCY}

doi:10.1136/thx.2010.150938.14

\begin{abstract}
${ }^{1} M-P$ Nyon, ${ }^{1} G$ Levy, ${ }^{1} J$ Kirkpatrick, ${ }^{2} U$ Ekeowa, ${ }^{2} D$ A Lomas, ${ }^{1} L$ D Cabrita, ${ }^{1} \mathrm{~J}$ Christodoulou, ${ }^{1}$ A McKay, ${ }^{1}$ B Gooptu. ${ }^{1}$ Institute of Structural and Molecular Biology, University College London and Birkbeck College, University of London, London, UK; ${ }^{2}$ Department of Medicine, University of Cambridge, Cambridge Institute for Medical Research, Cambridge, UK
\end{abstract}

Pathogenic mutations in the gene for $\alpha_{1}$-antitrypsin predispose to aberrant conformational transitions of the translated protein molecules resulting in their self-association to form polymer chains. Polymerisation causes circulating deficiency of $\alpha_{1}$-antitrypsin while predisposing to hepatic cirrhosis and severe, early-onset emphysema. Targeting the conformational transitions underlying polymerisation via ligand binding and stabilisation of the physiological native state is therefore a goal of drug design in $\alpha_{1}$-antitrypsin deficiency. To complement previous structure-led approaches we have developed NMR spectroscopy and nanospray mass spectrometry as mediumthroughput screening tools for such ligands. The coupling of these techniques combines highly sensitive detection of ligand binding with assessment of binding sites, stoichiometry, cooperativity and binding constants. We have used the TTAI peptide, developed within an existing programme of drug design, as a test case. The data demonstrate highly co-operative, slow, tight binding of two copies of the peptide in adjacent parts of the $\alpha_{1}$-antitrypsin molecule. TTAI peptide binding is shown to induce widespread conformational change all over the molecule with the exception of $\beta$-sheet C. These data prove the utility of NMR spectroscopy and nanospray mass spectrometry in characterising ligand binding whilst providing a highly detailed template for use in specific screening for TTAI peptide-mimetic compounds.

\section{S64 CHANGES IN PHYSIOLOGICAL PHENOTYPES OF $\alpha-1$-ANTITRYPSIN DEFICIENCY WITH TIME}

doi:10.1136/thx.2010.150938.15

H Ward, M R Miller, R A Stockley. Department of Respiratory Medicine, University Hospitals Birmingham NHS Foundation Trust, Birmingham, UK

Chronic Obstructive Pulmonary Disease (COPD), even due to $\alpha$-1antitrypsin deficiency (A1AD), is recognised as having distinct radiological, physiological and clinical phenotypes. Little is known about disease progression in physiologically defined phenotypes. ${ }^{1}$ We have identified a subgroup of patients with a reduced $\mathrm{FEV}_{1}$ but normal gas transfer determined by the lower limit of normal (LLN), that is, with standardised residual (SR) value $<-1.645$. The current abstract reports the progression of these physiological measures with time in this subgroup.

Methods 533 patients with A1AD were studied of whom 43 had isolated $\mathrm{FEV}_{1}$ abnormality at baseline and also had $\geq 3$ years of complete annual follow-up data. These patients were followed for a mean of 5.9 (2.2 SD) years. Of these, 22 remained with isolated $\mathrm{FEV}_{1}$ abnormality (Group A) whereas 21 had developed evidence of a reduced K,co deficiency (Group B). Group A and B data at baseline and at last follow-up were compared-see Abstract S64 Table 1.

Abstract S64 Table 1

\begin{tabular}{|c|c|c|}
\hline & $\begin{array}{l}\text { Group A Mean } \\
\text { (SD) } n=22\end{array}$ & $\begin{array}{l}\text { Group B Mean } \\
\text { (SD) } n=21\end{array}$ \\
\hline Age & $53.1(8.6)$ & $50.4(9.2)$ \\
\hline Males (\%) & 91 & 71 \\
\hline Pack year history & $20.0(15.7)$ & $18.1(18.2)$ \\
\hline Total SGRO & $56.5(16.8)$ & $40.8(11.3)^{*}$ \\
\hline Follow-up, years & $5.7(2.5)$ & $6.0(1.9)$ \\
\hline Baseline FEV 1 (L) & $1.53(0.5)$ & $1.44(0.5)$ \\
\hline Baseline $\mathrm{FEV}_{1} \mathrm{SR}$ & $-3.83(1.1)$ & $-3.87(1.1)$ \\
\hline Last $\mathrm{FEV}_{1} \mathrm{SR}$ & $-3.95(0.9)$ & $-4.04(1.1)$ \\
\hline $\mathrm{FEV}_{1}$ change (L/year) & $-0.038(0.03)$ & $-0.036(0.05)$ \\
\hline Baseline K,co (mmol/min/kPa/L) & $1.38(0.2)$ & $1.34(0.2)$ \\
\hline Baseline K,co SR & $-0.53(0.5)$ & $-1.01(0.5)^{* *}$ \\
\hline Last K,co SR & $-0.95(0.7)$ & $-2.19(0.6)^{*}$ \\
\hline $\mathrm{K}$, co change $(\mathrm{mmol} / \mathrm{min} / \mathrm{kPa} / \mathrm{L} /$ year $)$ & $-0.034(0.02)$ & $-0.061(0.03)^{* *}$ \\
\hline
\end{tabular}

Results There were no differences in $\mathrm{FEV}_{1}$, smoking, age or sex distribution between the groups. At baseline mean K,co SR was worse in Group B compared to Group A. However, Group A had significantly worse total Saint George's Respiratory questionnaire 